\title{
Effect of Modification of Lifestyle on Reproductive Potential
}

\author{
Yașam Tarzı Değișikliğinin Üreme Potansiyeline Etkisi
}

\author{
Turgut Aydın', Mert Ali Karadağ², Aslan Demir², Kürșat Çeçen², Yetkin Karasư ${ }^{3}$, Kahraman Ülker $^{3}$ \\ ${ }^{1}$ Acubadem Kayseri Hospital, In Vitro Fertilization Unit, Kayseri, Turkey, ${ }^{2}$ Department of Urology, Kafleas University School of Medicine, Kars, Turkey, \\ ${ }^{3}$ Department of Obstetrics and Gynecology, Kafkes University School of Medicine, Kars, Turkey
}

\begin{abstract}
Individuals have roles in preserving or increasing their fertility potential to a degree by controlling and modifying their life styles. Life styles modification may determine exposure to various factors that may improve or disprove reproductive health and fertility potential. Herein, we try to present some modifiable factors varies according to the life style preferences and their effects on reproductive health in the light of current medical literature.
\end{abstract}

Key words: behavior therapy; environment; infertility; life style; reproductive health

\section{ÖZET}

Bireyler yașam tarzlarını modifiye ve kontrol ederek, fertilite potansiyellerini bir dereceye kadar arttırabilir veya muhafaza edebilirler. Yașam tarzlarının modifikasyonu, üreme sağlığı ve fertilite potansiyelini arttıracak veya bozacak çeșitli faktörlere maruziyeti belirleyebilir. Bu makalede, yașam tarzı seçimlerine göre değișebilecek modifiye edilebilir bazı faktörleri ve onların üreme sağlığına olan etkilerini güncel tıbbi literatür eșliğinde sunuyoruz.

Anahtar kelimeler: davranıș terapisi; çevre; infertilite; hayat tarzı; üreme sağlığı

\section{Introduction}

Fertility is the capability of producing an offspring and the lack of fertility is defined as infertility. In daily practice, infertility is diagnosed in case where a couple desiring a pregnancy cannot get it in one year without the use of a contraceptive method. Normally $90 \%$ of couples get pregnant in a year time. Infertility rate, although may change in different populations, is around $15 \%$ in developed countries ${ }^{1,2}$. In modern health practice, quite a lot number of health institutes

Yard. Doç. Dr. Mert Ali Karadă̆, Kafkas Üniversitesi Tip Fakültesi Ürolöi Anabilim Dal, Kars, Türkije, Tel. 05325584324 Email.karadagmer@@yahoo.com

Gelis Taribi: 17.02.2014 - Kabul Taribi: 29.03.2014 and organizations have been working to reduce infertility rate by preventing its occurrence or treating the infertile couples.

The most effective treatment method of infertility is to fix the condition causing infertility. Sometimes, this goal may be achieved easily just by changing the sexual behavior of the couple. In contrary, sometimes the most recently developed technological treatment choices may be ineffective. Among the various types of treatment options, one may effective in one couple but ineffective in another. Although, health care providers may provide modern and appropriate treatment options for the couples suffering from infertility, the couples may also add something to preserve or increase their fertility potential by controlling and modifying their life styles. Life styles modification may determine exposure to various factors that may improve or disprove reproductive health and fertility potential.

In this paper, we aimed to review the effect of some modifiable factors associated with infertility.

\section{Smoking}

Cigarette contains over 400 pernicious chemicals, and cigarette smoking affects people adversely in a broad spectrum of diseases including pulmonary, cardiovascular and malignant diseases. Similarly, infertility is also found to be associated with smoking.

A tendency of decrease of the total sperm count, density, motility, normal morphology, semen volume, and fertilization capacity was observed in male smokers. Calogero et al. reported that smoking impaired the mitochondrial activity of spermatozoa 
and decreased fertilization capacity and they demonstrated that smoking increased DNA damage rate of the speramtozoa ${ }^{3}$.

Smoking is also associated with infertility in women, probably by deteriorating the ovarian functions and decreasing ovarian reserves ${ }^{4}$. In a recent study, Caserta et al investigated the influence of cigarette smoking on a population of infertile women. Antral follicle count (AFC), follicle stimulating hormone (FSH), luteinizing hormone (LH) and estradiol were measured in 296 women (194 non-smokers and 102 smokers). AFC was lower in smokers in comparison with the non-smokers and FSH levels were higher in smoking women, although estradiol and LH levels were not significantly different. Depending on their findings, the authors concluded that smoking had an unfavorable effect on ovarian reserve.

\section{Alcohol Consumption}

A large number of studies have so far been published on the effects of alcohol on health and fertility. While the relationship between alcohol and infertility has been well demonstrated in the majority of those studies, the harmful dosage of consumed alcohol is not precisely known.

Sperm morphology is affected by alcohol consumption. A prospective autopsy study investigated the relationship among alcohol consumption, spermatogenesis and morphometric analysis of human testis ${ }^{5}$. The autopsy series compared the findings of non-alcohol users (daily intake $<10 \mathrm{~g}$ ) and heavy drinkers (daily intake $>80 \mathrm{~g}$ ). Among nonalcohol users, $81.3 \%$ had normal spermatogenesis, whereas the remaining $18.7 \%$ had partial arrest of spermatogenesis. A significant lower percentage of heavy drinkers $(36.4 \%)$ had normal spermatogenesis, besides this $52.3 \%$ showed partial or complete arrest of spermatogenesis. The mean weight of testicles of heavy drinkers was significantly lower than of the non-alcohol users.

Alcohol consumption by women is also associated with infertility. In a study conducted in 7393 women, women consuming excessive amounts of alcohol had infertility-related scanning more often than those who consumed alcohol moderately $(R R=1.59$, CI 1.09-2.31) and those who consumed little alcohol $(\mathrm{RR}=0.64$, CI 0.46-0.9). In addition, increased frequency of alcohol intake, from once a week to
5 times a week, lengthened the time for conception $(\mathrm{p}=0.04 \text {; CI-0.95, CI }=0.85-1.10)^{6}$. Researchers thought that alcohol caused fluctuations in the hormonal levels and inhibited ovulation and folliculogenesis ${ }^{7}$. However, the lack of the standardization of the quantity of the consumed alcohol limited the evidence obtained from this study.

\section{Exercise}

Regular exercise and physical activity have beneficial effects on both reproductive and general health of men. The sperm parameters of men performing exercise of one hour, at least three times a week, are significantly more favorable than the sperm parameters of their counterparts performing exercise less frequently or more excessively ${ }^{8}$. Assessment by Kruger criteria revealed that men performing moderate physical activity had higher ratio of normal sperm morphology $(15.2 \%)$ than the men engaged in competitive sports $(9.7 \%)$, and professional athletes $(4.7 \%, \mathrm{p}<0.001)^{8}$. Although the difference was significant as in the case of sperm morphology, similar findings were obtained during the assessment of total sperm count, concentration and motility.

Moderate exercise and physical activity in women had positive effects on fertility. A population based health survey investigated the physical activity and fertility in 3887 women under 45 years old and found that higher frequency, duration and intensity of physical activity were associated with higher rates of sub-fertility $^{9}$. In addition, higher physical activity frequency was associated with voluntary childlessness $(p<0.01)$. After adjustment for parity, age and marital status, women who were active on most days were found to be 3.2 times more likely to have fertility problems in comparison with inactive women. Exercising to exhaustion was associated with 2.3 times the odds of fertility problems versus low intense physical activity. The explanation was suggested to be the negative energy balance led to hypothalamic dysfunction, causing fluctuations in the secretion of gonadotropinreleasing hormone, $(\mathrm{GnRH})$.

\section{Obesity}

Currently obesity is one of the most significant health problems, particularly in developing and developed countries. The change in the nutritional habits and busy working hours caused the consumption of fast food products with high caloric contents. 
Weight of a human being is not only affected by the food supplies, but the nutritional habits and physical activity level, as well. While assessing the weight status of an individual using body mass index (BMI) is more objective than assessments just with the weight. BMI levels below 18.5, between 18.5 and 24.9, over 25 and above 30 are classified as low weight, normal, overweight and obese, respectively.

BMI values related with fertility, and it was found in a study that a three $\mathrm{kg} / \mathrm{m}^{2}$ increase of BMI had adversely affected fertility (OR 1.12) ${ }^{10}$. The quality and concentration of semen and the motility of sperms were lower and the rate of sperm DNA damage was higher in obese men in comparison with the men having normal $\mathrm{BMI}^{11}$.

Leptin has roles in hunger control, inflammation, and insulin secretion, thus is related with the regulation of the body weight. A study on rats revealed that obese rats secreted five times higher leptin in comparison with weak rats. The higher leptin level was related with the five times higher infertility rate of the obese rats ${ }^{12}$. Fewer leptin receptors in the testicles of the male rats causing a leptin resistance were another finding of the study. The finding might play a role in male infertility ${ }^{12}$.

Medical literature consists of studies reporting that obesity affects fertility and pregnancy in women as well. A very recent study assessed the impact of significant weight loss on fertility outcomes in an overweight population with infertility ${ }^{13}$. Fifty-two overweight patients with a BMI of $>25$ were referred to weight loss counseling. The goal was to achieve a $10 \%$ loss of the actual body weights. An endocrinologist provided diet and exercise recommendations. The main outcome measures of the study were live birth, pregnancy and weight loss rates. Thirty-two percent of the patients succeeded significant weight loss and achieved significantly higher conception $(88 \%$ versus $54 \%)$ and live birth rates $(71 \%$ versus $37 \%$ in comparison with the ones could not succeed significant weight loss. The authors concluded that weight loss significantly improved the live birth rates in overweight infertile patients.

\section{Eating and Nutritional Disorders}

Obesity is not the only body weight disorder associated with the disorders of fertilization. Sperm concentration of the men with low weight was low compared with their counterparts with normal BMI ${ }^{14}$. Further studies on the topic are required, since the published studies have particularly focused on the effects of obesity and sperm parameters.

Reproductive health outcomes in women having eating disorders were investigated in a paper from Finland ${ }^{15}$. Female patients $(n=2257)$ treated at the eating disorder clinics of Helsinki University Central Hospital between 1995 and 2010 were compared with matched controls identified from the Central Population Register ( $\mathrm{n}=9028)$. Patients were diagnosed as anorexia nervosa, atypical anorexia nervosa, bulimia nervosa, atypical bulimia nervosa and binge eating disorder. Patients with eating disorders were more likely to be childless than controls $(\mathrm{p}<0.001)$, and pregnancy and child birth rates were lower compared with controls. The miscarriage risk was higher in patients with eating disorders $(p=0.002)$. In addition, in another study nutritional disorders were observed in $20.7 \%$ of the women undergoing intra uterine insemination ${ }^{16}$.

\section{Psychological Stress}

Stress, whether physical, social, or psychological, is an important factor of modern life. Stress may cause infertility and it may be resulted from infertility. Social pressures, diagnostic tests, unfavorable diagnosis, theuropathic procedures, treatment failures, repeated trials and the expenditures may encounter into stress.

Sperm concentration, motility and normal morphology ratios were low in men who had experienced grave stress more than twice throughout their lives in a study conducted on 950 male patients ${ }^{17}$. Occupational or social stress had significant unfavorable effects on sperm density, total sperm count, forward motility, and morphology ${ }^{17}$. In addition, stress in association with depression impaired gonad functions and effected adversely the spermatogenesis and semen parameters by decreasing testosterone and increasing $\mathrm{LH}$ and FSH levels ${ }^{18}$. There is no consensus, at present time, on whether low testosterone is the cause or result of depression, and therefore, further studies on this topic are necessary.

The elements of psychological stress, such as anxiety disorders or depressions, were observed in women applied to infertility clinics ${ }^{19}$. A comparative study between men and women in terms of anxiety, depression and self-esteem showed that infertile women had higher scores than their spouses had in several items 
like phobias, obsessive symptoms, somatization and interpersonal sensitivity ${ }^{19}$. Scores of hospital anxiety and depression scale were higher in women and the authors concluded that women suffered more severe psychological stress than men.

\section{Nutrition}

One of the fundamentals of a healthy life is to consume a variety of balanced and nutritive foods. Certain food groups and vitamins have greater effects on reproductive health than others do. Consumption of fibers, folate, lycopene, high carbohydrate food, fruit, (OR 2.3) and vegetable (OR 1.9) improves the semen quality ${ }^{20,21}$. Similarly, animal fat and protein consumption improves fertilization ${ }^{20}$.

Antioxidants eliminate reactive oxygen radicals (ROR) and improve fertility rates. ROR, a subgroup of free radicals, includes superoxide anion $\left(\mathrm{O}_{2}\right)$, hydrogen peroxide $\left(\mathrm{H}_{2} \mathrm{O}_{2}\right)$ and hydroxyl $(\mathrm{OH})$ radicals. RORs contain also nitrogen radicals composed of the derivatives of nitric oxide (NO), nitric dioxide $\left(\mathrm{NO}_{2}\right)$ and peroxynitrite (ONOO). ROR are necessary for certain cellular activities such as sperm capacitation. However, excessive ROR may deteriorate sperm motility, function and quality, and lead to DNA damage ${ }^{22}$.

Molecules categorized as antioxidants include ascorbic acid, $\alpha$-tocoferol, $\beta$-carotene, glutathione, uric acid, bilirubin or superoxide dismutase, catalase and glutathione peroxidase. Oxidative stress is the situation in which the quantity of ROR in the cellular matrix exceeds the amount that can be accommodated by antioxidants. It can damage sperm protein, lipidin, DNA and lead to sperm dysfunction ${ }^{22}$. Antioxidants may also differ in efficacy; Mendiola demonstrated that vitamin $\mathrm{C}$ enhanced semen quality to a significant degree when compared with vitamin $\mathrm{E}$ and selenium $(\mathrm{n}=61, \mathrm{p}<0.05)^{20}$.

The content of the diet affects fertility capacity of a woman by affecting ovulation. In a recent study from Iran, the investigators searched the influence of dietary fat intake on oocyte competence and embryo quality ${ }^{23}$. The study included 236 women undergoing assisted reproduction program. Follicular fluid was collected from these women and malondi-aldehyde (MDA) and total antioxidant capacity (TAC) levels were assessed as oxidative stress biomarkers. The MDA level in follicular fluid was related positively with the polyunsaturated fatty acids intake level $(p=0.02)$ and negatively with the cleavage rate $(\mathrm{p}=0.045)$. Polyunsaturated fatty acids intake levels were also negatively associated with mean number of blastomers $(p=0.006)$ and cleavage rate $(p=0.005)$. The study concluded that fat rich diet might induce the oxidative stress in oocyte environment and negatively influence embryonic development.

\section{Medications and Drug Abuse}

Owing to ethical concerns, it is extremely difficult to make a research dealing with the effects of drug abuse on fertility. Another impediment is that the prenatal care, in itself, of the women who abuse drugs and have low socio-economic status is already deplorable. Although drug abuse appears to have an adverse effect on fertility, further studies on this title, broad-based and approved by the ethical committee, are required.

Marijuana is one of the drugs most frequently used worldwide and may disprove reproductive functions ${ }^{24}$. It contains hashish, which is capable of binding to the receptors in reproductive organs such as uterus and ductus deference. Chronic use of marijuana (smoking marijuana at least 4 days for 6 months) decreases testosterone secretion from leydig cells, spermatogenesis, sperm capacitation, sperm motility and acrosome reaction, and increases apoptosis of sertoli cells ${ }^{24}$.

Women using marijuana are at greater risk of primary infertility in comparison with the women do not use marijuana (RR 1.7 CI 1.0-3.0) ${ }^{25}$. In addition, marijuana and hashish may disprove placental function and fetal development, and even may cause still births ${ }^{25}$.

Cocaine is another substance with a common worldwide use. It is a local anesthetic, however may be used because of its stimulating effects on the peripheral and central nervous system. It also may cause vasoconstriction. Rats chronically exposed to cocaine at the level of heavy users (15 mg/kg body weight) had pregnancy rates of $33 \%$ and $50 \%$ for 100 and 150 days of cocaine exposure, in contrary the rats without exposure during the same period had pregnancy rates of $86 \%$ and $100 \%$, respectively ${ }^{26}$.

\section{Prescribed Medicines}

Most of the published data dealing with the topic are on male infertility. In their recently published study, Hayashi et al. investigated the effects of antibiotics, 
anti-depressants, anti-epileptics, $\beta$-stimulators, H1 and $\mathrm{H} 2$ receptors antagonists, mast cell blockers and sulfonylurea on male infertility ${ }^{27}$. Of 1768 infertile males, 201 patients were taking these medications and had impaired semen quality without any seminal tract obstruction, spermatogenic abnormalities or hypogonadotropic hypogonadism. Of these 201 men, a total of 165 had no history of testicular diseases nor abnormalities in any examinations. Amongst them, $\mathrm{H} 1$ receptor antagonists were the most common medication taken, followed by antiepileptics and antibiotics. They were divided into two groups as an intervention group (73 patients), who could stop or switch their medications, and a control group (92 patients), who could not. Enhancement was observed in the semen quality of the patients in the first group, and pregnancy occurred in $85 \%$ of their wives within $12.5 \pm 0.64$ months. Besides this, improvement in semen quality was observed only in $12 \%$ of the controls, and pregnancy occurred in $10 \%$ of their wives.

The relationship between non-steroidal anti-inflammatory drugs and female fertility was pointed in a review by Stone et $\mathrm{al}^{28}$. They mentioned that three case series highlighted this possible relationship. The inhibition of cyclo-oxygenase (COX) isoenzyme was thought to cause luteinized unruptured follicle (LUF) syndrome, an anovulation condition characterized by clinical signs of ovulation but in the absence of follicular rupture and ovum release. Mice with COX-2 deficiency have severely compromised ovulation in the presence of apparently normal follicular development. The authors concluded that there was a strong correlation between non-steroid anti-inflammatory drug (NSAIDs) use and female infertility.

\section{The Reproductive Age}

Age of men and women directly related with the fertility capacity. Fertility peaks at puberty, and diminishes over time in both men and women. Stone et al. reported that total sperm number and total motility declined from the age of 34 years onward. Normal sperm morphology and concentration decreased after 40 years. Progressive motility and total motility of sperm decreased after 43 years and ejaculate volume decreased after $45^{29}$. While more sperm DNA damage was observed after the age of 40 , motility and viability decreased below $40 \%$ and $50 \%$, respectively $(\mathrm{n}=504, \mathrm{p}<0.001)^{30}$. The disprove of the semen parameters may be ascribed to life style factors such as greater alcohol consumption, decrease in the frequency of sexual intercourse, and smoking in greater quantities, as well as the older age itself.

The reproductive period in women has mechanisms that are more complex. Females are born with all their oocytes all ready produced. However, only 400 or 500 of the oocytes are ovulated during the reproductive years of a woman. As the number of oocytes diminishes, women's menstrual cycle shortens, and menstrual irregularities begin 6-7 years before menopause. While the chance of conception below the age of 30 years is $71 \%$, it falls down to $41 \%$ above the age of 36 years. The chance of not only becoming pregnant but also of sustaining it healthily is affected ${ }^{6}$. In addition, the chance of chromosomal abnormalities and aneuploidy increases with the advancing age and thus the chance of spontaneous miscarriage and implantation failure also increases.

\section{Caffeine Consumption}

Caffeine is consumed daily as a part of many foods and drinks. A large number of products including coffee, chocolate and fizzy drinks contain caffeine. Caffeine is thought to affect particularly female fertility.

It was determined that, with daily caffeine consumption over $500 \mathrm{mg}$, the time for occurrence of pregnancy exceeded 9.5 months (OR 1.45, 95\% CI 1.03$2.04)^{31}$. In a recent study, the influence of maternal caffeine consumption on reproductive parameters and fertility in male offspring rats was examined ${ }^{32}$. Pregnant rats received caffeine mixed with drinking water during gestation and lactation. Sperm parameters, fertility rate, testosterone level, reproductive organ weight, seminiferous tubule diameter and number of implantations of the male offspring were assessed. The body weight and the weight of the reproductive organ and the diameter of the seminiferous tubules were significantly decreased. Sperm density had declined in the offspring of the low dose and high dose groups by, $8.81 \%$ and $19.97 \%$, respectively. Testosterone levels of the high dose group also reduced. The authors finally concluded that maternal caffeine consumption might impair the structural and functional development of the gonads in male offspring of rats. 


\section{Cellular Phones and Radiation}

Exposure to radiation in varying doses and types has long-term effects. $\mathrm{X}$ and gamma rays, which are forms of radiation, may particularly affect germ cells and leydig cells. The adverse effect on fertility may be irreversible depending on the age of the patient and the intensity of the radiation ${ }^{33}$. There are also studies on the detrimental effects of cellular phones on fertility ${ }^{34,35}$.

Mobile phones transmit or receive radio-frequency electromagnetic waves that may have adverse effects on the fertility capacity. Some studies showed that cellular phone use was associated with diminished sperm number and motility, impaired sperm morphology, increased quantity of free radicals in the semen $^{34,35}$. Gutschi et al. also reported a higher serum free testosterone and a lower LH level of patients using cellular phones in comparison with the patients do not use cellular phones ${ }^{35}$. In addition, carrying their phones at waist level caused a $49.3 \%$ decrease in sperm motility of 52 compared with the men do not use cellular phones. The decrease rate was statistically significant $(\% 55.4 \pm 7.4 ; \mathrm{p}<0,001)^{36}$.

\section{Vaginal Lubricants}

Multitudes of sexually active couples prefer vaginal lubricants for eliminating pain and vaginal dryness during sexual intercourse. Most non-commercial lubricants contain olive oil, vegetable oil, and saliva, all of which have negative effects on sperm functions. In a recent study, nine commercial lubricants were compared in terms of the effects on sperm functions ${ }^{37}$. The compared lubricants in this in vitro investigation were Sylk ${ }^{\circledR}$, Conceive Plus ${ }^{\circledR}$, glycerol, Johnson's ${ }^{\circledR}$ Baby oil, SAGE ${ }^{\circledR}$ Culture Oil, Yes ${ }^{\circledR}$, Forelife $^{\mathrm{TM}}$, MaybeBaby ${ }^{\circledR}$ and Pre-seed ${ }^{\circledR}$. The authors reported that Pre-seed ${ }^{\circledR}$ and Forelife ${ }^{\mathrm{TM}}$ had the best and worst results in terms of vitality with the rates of $92 \%$ and $28 \%$, respectively. In terms of motility, Pre-seed ${ }^{\circledR}$ resulted in the highest percentage of spermatozoa with progressive motility of $86 \%$ and Sylk ${ }^{\circledR}$ showed the lowest percentage of progressivity with a rate of $31 \%$. There were no significant differences in DNA integrity.

\section{Doctor Visits}

Routine doctor visits and checkups may have beneficial effects on fertility. In reality, men do not very often try to get treatment for their sexual dysfunctions and infections. Of the men with sexual problems, only $10.5 \%$ consulted physicians for help ${ }^{38}$. In case where the symptoms lasted, the ratio of men consulting a physician would increase to $20.5 \%{ }^{39}$. The majority of men did not apply to a doctor because they were not aware of treatment options and guidance.

Women having regular gynecological visits with PAP smear screenings usually had better reproductive health outcomes. In addition, women with a better general health status also had a better reproductive health status ${ }^{40}$.

\section{Occupational Risk Factors and Heavy Metals}

Working environment of many people may increase the risks of exposure to various chemicals that have potential adverse effects reproductive health. In addition to the adverse effects of heavy metals exposed with the industrial products, residues of insecticides were encountered in higher quantities in the urine of men engaged in gardening as a hobby, in agricultural fields and greenhouses, and the situation decreased the semen quality and sperm motility ${ }^{41}$.

Exposure to organic solvents also affects fertility rates. The implantation rates were lower in the spouses of men contacted with the solvents ${ }^{42}$.

The class of metals known as heavy metals includes lead, mercury, boron, aluminum, cadmium, arsenic, antimony, cobalt, and lithium. There is a paucity of studies on the effects of heavy metals on reproduction. One of the heavy metals used in largest part in batteries, paints, and in ceramic industry is lead. Lead and boron act on hypothalamo-pituitary axis, change the hormone levels, delay puberty, and reduce the fertility rates ${ }^{43}$. Lead can impair sperm quality in men, and cause irregular menstruation and spontaneous pregnancy losses in women ${ }^{43}$.

Mercury is mostly used in thermometers, batteries and industrial wastes. Mercury concentration can rise in food chain, which in turn, can cause biological accumulation and compromise reproductive functions of people who consume rotten sea products. It can impair particularly spermatogenesis, and affect fetal development adversely ${ }^{43}$.

\section{Clothing}

Men's way of clothing may affect reproductive health. A large number of studies have sought answers to 
the question of what type clothing has the most favorable impact on fertility. It is thought that tight clothing raises scrotal temperature and thus affects spermatogenesis. In a study, 20 voluntary men wore tight underwear for 6 months and then loose-fitting underwear for another 6 months. The semen samples were analyzed in every two weeks. Although half of the participants did not continue the study, semen parameters decreased by a $50 \%$ during the first 6 months. However, the decrease was temporary ${ }^{44}$. In another study, the influence of wearing boxer shorts on male sub-fertility was investigated ${ }^{45}$. Scrotal temperatures and semen analyses were obtained in 97 consecutive men for evaluation of clinical sub-fertility. The participants were divided by underwear type to boxer or brief group. Unlike the results of aforementioned paper, the authors observed no significant differences in temperatures and semen parameters between two groups ${ }^{45}$.

\section{Air Pollution}

Gases such as sulfur dioxide, carbon monoxide, nitrate dioxide, particles, and ozone are released into the atmosphere from the exhaust of motor vehicles, as industrial waste from burning coal and wood, or from other sources. Regarding the effects of air pollution on human health and relevant measures, significant developments have been witnessed especially in the last decade. However, the effect of air pollution on human fertility is known little.

In Czech Republic, men living in two different residential areas, and therefore, exposed to air pollution in varying degrees were compared in terms of their fertility potentials ${ }^{46}$. Sperm DNA damage was observed more extensively and often in the semen samples of men exposed more intense air pollution.

Air pollution has adverse effects on female fertility. It was reported that air pollution lead to preterm births, miscarriages, spontaneous pregnancy loss, or fetal demise ${ }^{43}$. An animal study investigated the relationship between female fertility and air pollution in the city of Sao Paulo ${ }^{47}$. Mice were divided into two groups as living in a clean chamber (receiving clean air) and a polluted chamber (receiving ambient air). Fertility parameters decreased only in animals exposed to air pollution at an earlier age (10 days after birth). Higher number of live born pups per animal was found in the clean chamber group $(p=0.037)$ and higher incidence of implantation failures $(p=0.048)$ was observed in the polluted group.

\section{Effect of Heat}

In a study conducted by Shefi et al., 11 male subjects were asked to keep away from wet heat for three months after being exposed to wet heat over 30 minutes a week for a three month period ${ }^{48}$. The semen samples of the participants were analyzed at beginning, 3rd month, and between 3rd and 6th months. An improvement in the semen quality was observed in nearly half of the subjects, and an acceleration of $22 \%$ was observed in the sperm motility in the subjects with improved semen quality. This acceleration continued longer than 3 months $(p=0,02)$. In this study, other life style factors like smoking were blamed for the subjects failing to respond to treatment.

\section{Contraceptives}

Although contraceptive methods are practiced to prevent unintended pregnancies, their use contributes to better fertility rates and the users of condoms and oral contraceptives have more properly working reproductive organs ${ }^{6}$. The women who consider themselves infertile use contraceptives less often, in fact.

Cessation of contraceptive use can shorten the time needed till the conception. In a recent study following the decision for a pregnancy and cessation of the contraceptive methods, couples using condoms achieved pregnancy sooner than the couples using oral contraceptives, and the couples using oral contraceptives achieved pregnancy sooner than the couples without a contraceptive method ${ }^{49}$. Another finding from the same study was that oral contraceptives had preventive and therapeutic effects on endometriosis and pelvic inflammatory disease. It was accepted that use of contraceptives enhanced female fertility and in turn the chance of giving birth.

\section{Conclusion}

Individual ways of living and environmental conditions, like their effects on general health, also influence the reproductive health. Fortunately, most of the aforementioned factors are modifiable and the modification is usually costless. In addition to its beneficial effects on reproductive health life style modification also improves general health. 


\section{References}

1. Homan GF, Davies M, Norman R. The impact of lifestyle factors on reproductive performance in the general population and those undergoing infertility treatment: a review. Hum Reprod Update 2007;13:209-3.

2. Maruani P, Schwartz D. Sterility and fecundability estimation. J Theor Biol 1983;105:211-9.

3. Calogero A, Polosa R, Perdichizzi A, et al. Cigarette smoke extract immobilizes human spermatozoa and induces sperm apoptosis. Reprod Biomed Online 2009;19:564-71.

4. Caserta D, Bordi G, Di Segni N, et al. The influence of cigarette smoking on a population of infertile men and women. Arch Gynecol Obstet 2013;287:813 8.

5. Pajarinen JT, Karhunen PJ. Spermatogenic arrest and 'Sertoli cell-only' syndrome-common alcohol induced disorders of the human testis. Int J Androl 1994;17:292-9.

6. Mutsaerts MA, Groen H, Huiting HG, et al. The influence of maternal and paternal factors on time to pregnancy-a Dutch population based birth-cohort study: the GECKO drenthe study. Hum Reprod 2012;27:583-93.

7. Eggert J, Theobald H, Engfeldt P. Effects of alcohol consumption on female fertility during an 18-year period. Fertil Steril 2004;81:379-83.

8. Vaamonde D, Da Silva-Grigoletto ME, Garcia-Manso JM, et al. Response of semen parameters to three training modalities. Fertil Steril 2009;92:1941-6.

9. Gudmundsdottir SL, Flanders WD, Augestad LB. Physical activity and fertility in women: The North Trondelag health study. Hum Reprod 2009;24:3196-204.

10. Sallmen M, Sandler DP, Hoppin JA, et al. Reduced fertiliy among overweight and obese men. Epidemiology 2006;17:520-3.

11. Martini AC, Tissera A, Estofan D, et al. Overweight and seminal quality: a study of 794 patients. Fertil Steril 2010;94:1739-43.

12. Ghanayem BI, Bai R, Kissling GE, et al. Diet-induced obesity in male mice is associated with reduced fertility and potentiation of acrylamide-induced reproductive toxicity. Biol Reprod 2010;82:96-104.

13. Kort JD, Winget C, Kim SH, et al. A retrospective cohort study to evaluate the impact of meaningful weight loss on fertility outcomes in an overweight population with infertility. Fertil Steril 2014 doi:10.1016/j.fertnstert.2014.01.036.

14. Chavarro JE, Toth TL, Wright DL, et al. Body mass index in relation to semen quality, sperm DNA integrity, and serum reproductive hormone levels among men attending an infertility clinic. Fertil Steril 2010;93:2222-31.

15. Linna MS, Raevuori A, Hakka J, et al. Reproductive health outcomes in eating disorders. Int J Eat Disord 2013;46:82633.

16. Freitzinger M, Franko DL, Dacey M, et al. The prevalance of eating disorders in infertile women. Fertil Steril 2010;93:72-8.
17. Gollenberg AL, Liu F, Brazil C, et al. Semen quality in fertile men in relation to psychosocial stress. Fertil Steril 2010;93:1104-11.

18. Bhongade MB, Prasasd S, Jiloha RC, et al. Effect of psychological stress on fertility hormones and seminal quality in male partners of infertile couples. Andrologia 2014 doi: 10.1111/and.12268.

19. El Kissi Y, Romdhane AB, Hidar S, et al. General psychopatology, anxiety, depression and self-esteem in couples undergoing infertility treatment: a comparative study between men and women. Eur J Obstet Gynecol Reprod Biol 2013;167:185-9.

20. Mendiola J, Torres-Cantero AM, Vioque J, et al. A low intake of antioxidant nutrients is associated with poor semen quality in patients attending fertility clinics. Fertil Steril 2010;93:1128-33.

21. Wong WY, Zielhuis GA, Thomas CM, et al. New evidence of the influence of exogenous and endogenous factors on sperm count in man. Eur J Obstet Gynecol Reprod Biol 2003;110:49-54.

22. Cocuzza M, Sikka SC, Athayde KS, et al. Clinical relevance of oxidative stress and sperm chromatin damage in male infertility: an evidence based anaysis. Int Braz J Urol 2007;33:603-21.

23. Kazemi A, Ramezanzadeh F, Nasr-Esfahani MH, et al. Does dietary fat intake influence oocyte competence and embryo quality by inducing oxidative stress in follicular fluid? Iran J Reprod Med 2013;11):1005-12.

24. Fronczak CM, Kim ED, Barqawi AB. The insults of illicit drug use on male fertility. Journal of Andrology 2012;33:515-28.

25. Park B, McPartland JM, Glass M. Cannabis, cannabinoids and reproduction. Prostaglandins Leukot Essent Fatty Acids 2004;70:189-97.

26. George VK, Li H, Teloken C, Grignon DJ, et al. Effects of long term cocaine exposure on spermatogenesis and fertility in prepubertal male rats. J Urol 1996;155:327-31.

27. Hayashi T, Miyata A, Yamada T. The impact of commonly prescribed drugs on male infertility. Hum Fertil(Camb)2008;11:191-6.

28. Stone S, Khamashta MA, Nelson-Piercy C. Nonsteroidal antiinflamatory drugs and reversible female infertility: is there a link? Drug Saf 2002;25:545-51.

29. Stone BA, Alex A, Werlin LB, et al. Age threshold for changes in semen parameters in men. Fertil Steril 2013;100):952-8.

30. Varshini J, Srinag BS, Kalthur G, et al. Poor sperm quality and advancing age are associated with increased sperm DNA damage in infertile men. Andrologia 2012;44:642-9.

31. Bolumar F, Olsen J, Rabagliato M, et al. European study group on infertility and sub fecundity. Caffeine intake and delayed conception: A European multicenter study on infertility and sub fecundity. Am J Epidemiol 1997;145:324-34.

32. Dorostqhoal M, Erfani Majd N, et al. Maternal caffeine consumption has irreversible effects on reproductive parameters and fertility in male offspring rats. Clin Exp Reprod Med 2012;39:144-52. 
33. Meirow D, Biederman H, Anderson RA, et al. Toxicity of chemotherapy and radiation on female production. Clin Obstet Gynecol 2010;3:727-39.

34. Agarwal A, Deepinder F, Sharma RK, et al. Effect of cell phone usage on semen analysis in men attending infertility clinic: An observational study. Fertil Steril 2008;89:124-8.

35. Gutschi T, Mohamad Al-Ali B, Shamloul R, et al. Impact of cell phone use on men's semen parameters. Andrologia 2011;43:312-6.

36. Kigallon SJ, Simmons LW. Image content influences men's semen quality. Biol Lett 2005;1:253-5.

37. Mowat A, Newton C, Boothroyd C, et al. The effects of vaginal lubricants on sperm function: an invitro analysis. J Assist Reprod Genet 2014;31:333-9.

38. Sharma R, Biedenharm KR, Fedor JM, et al. Lifestyle factors and reproductive health: taking control of your fertility. Reprod Biol Endocrinol 2013;11:66. doi: 10.1186/14777827-11-66.

39. Mercer CH, Fenton KA, Johnson AM, et al. Sexual function problems and help seeking behavior in Britain: National probability sample survey. BMJ 2003;327:426-7.

40. Kelly-Weeder S, Cox CL. The impact of lifestyle factors on female infertility. Women Health 2006;44:1-23.

41. Pant N, Pant AB, Chaturverdi PK, et al. Semen quality of environmentally exposed human population: the toxicological consequence. Environ Sci Pollut Res Int 2013;20:8274-81.
42. Tielemans E, van Kooij R, Looman C, et al. Paternal occupational exposures and embryo implantation rates after IVF. Fertil Steril 2000;74:690-5.

43. Chalupka S, Chalupka AN. The impact of environmental and occupational exposures on reproductive health. JOGNN 2010;39:84-102.

44. Tiemessen CH, Evers JL, Bots RS. Tight fitting underwear and sperm quality. Lancet 1996;347:1844-5.

45. Munkelwitz R, Gilbert BR. Are boxer shorts really better? A critical analysis of the role of underwear type in male subfertility. J Urol 1998;160:1329-33.

46. Rubes J, Selevan SG, Evenson DP, et al. Episodic air pollution is associated with increased DNA fragmentation in human sperm without other changes in semen quality. Hum Reprod 2005;20:2776-83.

47. Mohallem SV, de Arauıo Lobo DJ, et al. Decreased fertility in mice exposed to environmental air pollution in the city of Sao Paulo. Environ Res 2005;98:196-202.

48. Shefi S, Tarapore PE, Walsh TJ, et al. Wet heat exposure: a potentially reversible cause of low semen quality in infertile men. Int Braz J Urol 2007;33:56-7.

49. Revonta M, Raitanen J, Sihvo S, et al. Health and life style among infertile men and women. Sex Reprod Health 2010;1:191-8. 